\title{
Quality of Life of Parents and Behavioral Aspects of Children with Autism Spectrum Disorders (ASD)
}

\author{
Nure Naznin ${ }^{1}$, Md. Obaidul Haque ${ }^{2}$, Akhi Akter ${ }^{3}$, Sultana Nasreen ${ }^{4}$, Md. Shahoriar Ahmed ${ }^{5 *}$ \\ ${ }^{1}$ Department of Speech \& Language Therapy, Bangladesh Health Professions Institute (BHPI), Savar, Dhaka-1343 \\ ${ }^{2}$ Department of Physiotherapy, Bangladesh Health Professions Institute (BHPI), Savar, Dhaka-1343 \\ ${ }^{3}$ Bangladesh Health Professions Institute (BHPI), Savar, Dhaka-1343 \\ ${ }^{4}$ Bangladesh Health Professions Institute (BHPI), Savar, Dhaka-1343 \\ ${ }^{5}$ Bangladesh Physiotherapy Association (BPA), Savar, Dhaka-1343
}

DOI: $10.36348 /$ jaspe.2020.v03i10.001 $\quad$ | Received: 19.09 .2020 | Accepted: 02.10 .2020 | Published: 10.10 .2020

*Corresponding author: Md. Shahoriar Ahmed

Email: physio.shahoriar@gmail.com

\section{Abstract}

Background: Parent quality of life refers to the degree to which parent of individuals of children with disabilities are able to meet their basic needs, enjoy time together, and pursue leisure interests and activities. Children with ASD causes stress in the family, most especially among parents, consequently affecting parental quality of life (QOL). Objective: Our objective was to identify the quality of life among the parents of children with autism spectrum disorder and behavioural aspects of children with autism spectrum disorder. Methods: This paper describes the QOL of parents and behavioural aspects of children with Autism Spectrum Disorders (ASD) by using a quantitative method design. The participants are parents of children with ASD $(n=153)$ and were asked to answer the World Health Organization Quality of Life-Brief (WHOQOL-BREF) Questionnaire Bengali Version and The Nisonger Child Behavior Rating Form (NCBRF). The WHOQOL-BREF was used to assess parental QOL while the Nisonger Child Behavior Rating Form (NCBRF) was used to assess the child's social behavior/ competence and problem behavior, demographic data were also obtained. Results: The result identified the significant association between parent's quality of life (physical domain, psychological domain, social domain and environment domain) with all the characteristics of children with ASDs problem behavior as conduct problem, anxious, hyperactive, stereotypic and self-isolated. The result showed that positive weak correlation between parent's quality of life (physical health, psychological, social relationships and environment) with children with ASD's social behavior $\left(0<r_{s}<0.25\right)$. Conclusion: For the problem behavior (conduct problem, insecure, hyperactive, self-injury and overly sensitive) of the children with ASD showed the positive correlation with respondent four domains of quality of life except self-isolation.

Keywords: Autism Spectrum Disorders (ASDs), Behavior and Quality of Life (QoL).

Copyright @ 2020: This is an open-access article distributed under the terms of the Creative Commons Attribution license which permits unrestricted use, distribution, and reproduction in any medium for non-commercial use (NonCommercial, or CC-BY-NC) provided the original author and source are credited.

\section{BACKGROUND}

Children makes the family inclusive and whenever a new member arrives at the family they bring more happiness, the family plays an important role in developing the child's abilities and skills, and possibly the presence of a disabled child in the family may represent a change point in lives of the entire family, it reorganizes the life and priorities for coping with new circumstances. On the other hand, when the child has any medical or developmental difficulty the family is influenced in a negative way and often life becomes wretched for them. A disabled individual has several negative side effects on the various aspects of life in various life cycle, some of which are linked to disability they have, or the family environment in which they live, their economic and social circumstances, educational environment they learn, or their cultural aspects, which would affect the quality of life of these individuals and their families. Autism Spectrum Disorder (ASD) is one such developmental condition whose incidence is increasing rapidly across the world. The term "Autism" is a life-long brain disorder that is normally diagnosed in early childhood. Autism spectrum disorders characterizes a spectrum of complex, neurological, and developmental disorders characterized by deficits in reciprocal social interaction and communication, along with the presence of restricted, repetitive, and stereotyped interests and behaviors [1]. These deficits manifest in early 
development and are pervasive in nature, affecting individuals throughout their lifespan [2]. Children with autism have complications in communicating, creating relationships with others and finding hard to make sense of the world around them [3]. Bangladesh is a developing country where the number of children with ASD is increasing in a remarkable manner. It has been estimated that $1 \%$ of world population is suffering from Autism which can be explained as a life-long neurodevelopment condition interfering with the person's ability to communicate and relate to others [4]. The complications connected to ASD not only affect the diagnosed individual but also his or her caregivers, family, teachers, and community. The prevalence rate in the United States for ASD is estimated approximately one in 88 children. This study showed that parental understanding and explanation of deficits is correlated highly with the way ASD is explained to them by treatment of professionals [5]. Parents of children with autism spectrum disorders face multiple challenges due to their child's developmental difficulties. Raising and supporting a child with an ASD appears to have negative effects on parents and families regardless of the severity of symptom or the time since diagnosis. According to Montes and Halterman, 39\% of parents of children with ASD reported that they faced many problems in their job affairs for childcare, compared to $9 \%$ of typically developing children. It has been showed that parents signified that they refrained from participating in activities outside the home because their attention was constantly on their children with autism because they felt that others did not understand the behavior problems of their children [6]. This study reported that parents of children with various developmental disabilities experience heightened stress, overburden and marginalization in society, sense of self accusation, tiredness or exhaustion, so the quality of life of the families of children with autism spectrum disorder is influenced by its varying degrees of behavioral problems. Children with ASD is often conceptualized as a risk factor in terms of family wellbeing, as there is additional stress placed on family relationships, as well as on family member's roles and responsibilities [7]. According to the World Health Organization's world report of disability [8], one of the main obstacles that hamper the establishment of efficient support programs for parents of children with Autistic Disorder in the developing countries is the lack of research studies that can inform about the psychosocial impacts of raising children with Autistic Disorder on their parents [9]. Parents of children with ASD appearance challenges place them at risk for higher levels of stress and difficulties in reciprocal interaction as well as communication and stereotypically difficult behaviors, which are related to ASD. Parents have an important role in sibling relationships, not only in normal children but also in children with ASD and they also take on responsibilities of diagnosis, advocacy, and daily care. Increasing incidence of autism and related spectrum disorders in recent years, no specific treatment and the significantly high morbidity make the most of the children can't fit into society, the prognosis is a long-term social problem, and therefore, attaching importance to and paying attention to the survival quality of the autistic children is urgent and necessary [10]. As parenting the children with ASD is emotionally, socially, financially, and physically challenging, mothers of children with autism are highly stressed more than the mothers of the normal children. Low quality of life among parents of children with autism spectrum disorder may later lead to various problems in their lives such as anxiety and introversion, social withdrawal, a sense of loneliness and loss of the meaning of life, the lack of efficiency in social relations and negative social behavior, and the failure to form and maintain friendships, emotional imbalance and others. Quality of life can be achieved for the family if their needs are satisfied, through various fields such as financial condition, family interaction and a healthy social life [11]. Parents of children with autism spectrum disorder face numerous challenges, including obtaining a diagnosis, finding appropriate treatment and educational programs, and struggling with the financial burden of paying for services and consequences of coping with these and many other challenges associated with raising a child with ASD, so that parents face greater levels of depression and higher levels of stress.

\section{METHODS}

This was a cross-sectional quantitative study design where data were collected by convenient sampling technique.

\section{Ethical Considerations}

Ethics approved was obtained from Institutional Review Board (IRB) of Bangladesh Health Professions Institute, CRP. Confidentiality was maintained strictly during the course of study and during every step of the research. No patients name and address was identified to the public domain and the entire document kept confidential.

\section{Data Collection}

Data were collected by using structured questionnaire. The questionnaire was Bangla translated by expert where demographic related question was setup and two checklists e.g. "WHOQOL BREF" and "THE NISONGER CHILD BEHAVIOR RATING FORM" were also inputted. Before commencement of data collection a consent form was developed based on inclusion and exclusion criteria for each participant.

\section{Setting and participants}

The study area was Bangladesh Health Professions Institute (BHPI). The study sample has been collected from the Centre for the Rehabilitation of the Paralyzed (CRP), Head office at Savar, and all other divisional branches of it situated in Mirpur-Dhaka, Rajshahi, Barishal, Sylhet and Chittagong. 
Analysis

Data were analyzed by using SPSS the statistical software for Windows, version 16.0.
Descriptive analysis of all relevant variables has done using measures of frequency; association within/ between variables were tested using chi square $(\chi 2)$ tests. The significance threshold was set to $\mathrm{p}<0.05$. Spearman's rank correlation coefficient was used to measure the correlation between variable.

\section{RESULTS}

Table-1: Demographic Information of parents and children with ASD

\begin{tabular}{|l|l|}
\hline Parents of Children with ASD (Respondent) & n (\%) \\
\hline Age, years & $35.37 \pm 6.828$ \\
\hline Age Category & $87(56.9)$ \\
\hline 22 Years-36 Years & $66(43.1)$ \\
\hline 37 Years-51 Years & $64(41.8)$ \\
\hline Relation with ASD children & $89(58.2)$ \\
\hline Father & $22(14.4)$ \\
\hline Mother & $18(11.8)$ \\
\hline Education & $26(17)$ \\
\hline Illiterate & $36(23.5)$ \\
\hline Primary & $36(23.5)$ \\
\hline Secondary & $15(9.8)$ \\
\hline Higher & $6.44 \pm 2.042(3-10)$ \\
\hline Graduate & $78(51.0)$ \\
\hline Post-graduate & $75(49.0)$ \\
\hline Children with Autism Spectrum Disorder (ASD) \\
\hline Age (years) & $87(56.9)$ \\
\hline Age category of children with ASD & $66(43.1)$ \\
\hline 3 Years to 6Years & \\
\hline 7 Years to10 Years & \\
\hline Gender of the children with ASD & \\
\hline Male & \multicolumn{2}{|l|}{} \\
\hline Female & \\
\hline
\end{tabular}

Table-1 Depict that there is a predominance of mother respondents $58.2 \%$ having mean age 35.37 years and standard deviation 6.828. The majority respondent's age category is 22 years to 36 years $(56.9 \%)$. Among the participants, about illiterate $14.4 \%$ $(\mathrm{n}=22)$, primary education completed $11.8 \% \quad(\mathrm{n}=18)$, secondary education completed $17.0 \%(\mathrm{n}=26)$, higher secondary education completed $23.5 \% \quad(n=36)$, graduation completed $23.5 \% \quad(\mathrm{n}=36)$ and postgraduation completed $9.8 \%(n=15)$. So that most of the respondent's education qualifications are higher secondary and graduated. Study group children had a mean age of 6.44 years and a standard deviation of 2.042 , and their age range from 3 to 10 years with male predominate $56.9 \% .78(51.0 \%)$ children with ASD lie between 3 and 6 years age group.

Table-2: Descriptive Statistics of Respondents Physical Health by WHOQOL-BREF

\begin{tabular}{|l|l|l|l|l|l|l|}
\hline Physical Health & 1 Poor QOL & 2 & 3 Medium QOL & 4 & 5 Good QOL & Total \\
\hline Pain and discomfort & $19(12.4)$ & $39(25.5)$ & $71(46.4)$ & $23(15.0)$ & $1(0.7)$ & $153(100)$ \\
\hline Energy and fatigue & $2(1.3)$ & $35(22.9)$ & $78(51.0)$ & $34(22.2)$ & $4(2.6)$ & $153(100)$ \\
\hline Sleep and rest & $10(6.5)$ & $48(31.4)$ & $46(30.1)$ & $42(27.5)$ & $7(4.6)$ & $153(100)$ \\
\hline Dependence on medication & $5(3.3)$ & $34(22.2)$ & $80(52.3)$ & $26(17.0)$ & $8(5.2)$ & $153(100)$ \\
\hline Mobility & $6(3.9)$ & $23(15.0)$ & $69(45.1)$ & $49(32.0)$ & $6(3.9)$ & $153(100)$ \\
\hline Activities of daily living & $6(3.9)$ & $32(20.9)$ & $59(38.6)$ & $48(31.4)$ & $8(5.2)$ & $153(100)$ \\
\hline Working capacity & $8(5.9)$ & $23(15.0)$ & $58(37.9)$ & $57(37.3)$ & $6(3.9)$ & $153(100)$ \\
\hline
\end{tabular}

From the Table-2 total participant was 153 for physical health of pain and discomfort showed that medium level $46 \%(n=71)$, poor level $12.4 \%(n=19)$, good level $0.7 \%(n=1)$. For energy and fatigue showed that medium level $78 \%(n=78)$, poor level $1.3 \%(n=2)$, good level $2.6 \%(n=4)$. For sleep and rest showed that medium level $30.1 \%(n=46)$, poor level $6.5 \%(n=10)$, good level $4.6 \%(n=7)$. In dependence on medication showed that medium level $52.3 \%(\mathrm{n}=80)$, poor level $3.3 \%(n=5)$, good level $5.2 \% \quad(n=8)$. The mobility showed that medium level $45.1 \%(n=69)$, poor level $3.9 \%(n=3)$, good level $3.9 \%(n=6)$. For the activities of 
daily living showed that medium level $38.6 \%(n=59)$, poor level $3.9 \%(n=6)$, good level $5.2 \%(n=8)$. And working capacity foe the participant showed that medium level $37.9 \%(\mathrm{n}=58)$, poor level $5.9 \%(\mathrm{n}=8)$, good level $3.9 \%(n=6)$.

Table-3: Descriptive Statistics of Respondents Psychological Domain by WHOQOL-BREF

\begin{tabular}{|l|l|l|l|l|l|l|}
\hline Psychological & $\begin{array}{l}\text { 1 Poor } \\
\text { QOL }\end{array}$ & $\mathbf{2}$ & $\begin{array}{l}\text { 3 Medium } \\
\text { QOL }\end{array}$ & $\mathbf{4}$ & $\begin{array}{l}\text { 5 Good } \\
\text { QOL }\end{array}$ & Total \\
\hline Positive feelings & $1(0.7)$ & $48(31.4)$ & $75(49.0)$ & $27(17.6)$ & $2(1.3)$ & $153(100)$ \\
\hline Negative feelings & $0(0)$ & $13(8.5)$ & $57(37.3)$ & $53(34.6)$ & $30(19.6)$ & $153(100)$ \\
\hline Self-esteem & $8(5.2)$ & $28(18.3)$ & $60(39.2)$ & $46(30.1)$ & $11(7.2)$ & $153(100)$ \\
\hline $\begin{array}{l}\text { Thinking learning, memory and } \\
\text { concentration }\end{array}$ & $1(0.7)$ & $42(27.5)$ & $70(45.8)$ & $39(25.5)$ & $1(0.7)$ & $153(100)$ \\
\hline Body image & $3(2.0)$ & $21(13.7)$ & $79(51.6)$ & $44(28.8)$ & $6(3.9)$ & $153(100)$ \\
\hline
\end{tabular}

This Table-3 Indicated that the respondent psychological health, for the positive feeling is showed good levels $1.3 \%(n=2)$, medium level are $49 \%(n=75)$ and poor level $0.7 \%(n=1)$. For the negative feelings showed that good levels are $19.6 \%(n=30)$, medium level are $37.3 \%(n=57)$. On the other hand self-esteem showed that good levels are $7.2 \%(n=11)$, medium level
$39.2 \%(n=60)$ and poor levels are $5.2 \%(n=8)$. For the thinking learning, memory and concentration showed that good levels are $0.7 \%(n=1)$, medium level $45.8 \%$ $(\mathrm{n}=70)$ and poor levels are $0.7 \%(\mathrm{n}=1)$. In the body image showed that good levels are $3.9 \%(n=6)$, medium level $51.6 \%(n=79)$ and poor levels are $2 \%(n=3)$.

Table-4: Descriptive Statistics of Respondents Social Relationships Domain by WHOQOL-BREF

\begin{tabular}{|l|l|l|l|l|l|l|}
\hline Social relationships & 1 Poor QOL & 2 & 3 Medium QOL & 4 & 5 Good QOL & Total \\
\hline Personal relations & $7(4.6)$ & $35(22.9)$ & $48(31.4)$ & $51(33.3)$ & $12(7.8)$ & $153(100)$ \\
\hline Sex & $2(1.3)$ & $24(15.7)$ & $45(29.4)$ & $71(46.4)$ & $11(7.2)$ & $153(100)$ \\
\hline Practical social support & $8(5.2)$ & $39(25.5)$ & $49(32.0)$ & $52(34.0)$ & $5(3.3)$ & $153(100)$ \\
\hline
\end{tabular}

In this Table-4 Showed that the descriptive statistics of respondents social relationship. For the personal relations showed that good levels are $7.8 \%$ $(n=12)$, medium level $31.4 \%(n=48)$ and poor levels are $4.6 \%(n=7)$. On the other hand sex showed that good levels are $7.2 \%(n=11)$, medium level $29.4 \%(n=45)$, and poor levels are $1.3 \%(\mathrm{n}=2)$. For the practical social support showed that good levels are $3.3 \%(\mathrm{n}=5)$, medium level $32 \%(\mathrm{n}=49)$ and poor levels are $5.2 \%$ $(\mathrm{n}=8)$.

Table-5: Descriptive Statistics of Respondents Environment Domain by WHOQOL-BREF

\begin{tabular}{|l|l|l|l|l|l|l|}
\hline Environment & 1 Poor QOL & 2 & 3 Medium QOL & 4 & 5 Good QOL & Total \\
\hline Financial resources & $20(13.1)$ & $27(17.6)$ & $71(46.4)$ & $29(19.0)$ & $6(3.9)$ & $153(100)$ \\
\hline Information and skills & $7(4.6)$ & $41(26.8)$ & $70(45.8)$ & $26(17.0)$ & $9(5.9)$ & $153(100)$ \\
\hline Recreation and leisure & $14(9.2)$ & $54(35.3)$ & $52(34.0)$ & $24(15.7)$ & $9(5.9)$ & $153(100)$ \\
\hline Home environment & $7(4.6)$ & $37(24.2)$ & $48(31.4)$ & $5(35.9)$ & $6(3.9)$ & $153(100)$ \\
\hline Access to health and social care & $8(5.2)$ & $39(25.5)$ & $45(29.4)$ & $54(35.3)$ & $7(4.6)$ & $153(100)$ \\
\hline Physical safety and security & $3(2.0)$ & $47(30.7)$ & $41(46.4)$ & $29(19.0)$ & $3(2.0)$ & $153(100)$ \\
\hline Physical environment & $7(4.6)$ & $45(29.4)$ & $65(42.5)$ & $32(20.9)$ & $4(2.6)$ & $153(100)$ \\
\hline Transport & $15(9.8)$ & $37(24.2)$ & $42(27.5)$ & $57(37.3)$ & $2(1.3)$ & $153(100)$ \\
\hline
\end{tabular}

The Table-5 showed that the descriptive statistics of respondent environment domain. For the financial resources showed that good levels are $3.9 \%$ $(\mathrm{n}=6)$, medium level $46.4 \%(\mathrm{n}=71)$ and poor levels are $13.1 \%(n=20)$. Information and skills showed that good levels are $5.9 \%(n=9)$, medium level $45.8 \%(n=70)$ and poor levels are $4.6 \%(n=7)$. Recreation and leisure showed that good levels are $5.9 \%(n=9)$, medium level $34 \%(n=52)$ and poor levels are 9.2\% $(n=14)$. Home environment showed that good levels are $3.9 \%(n=6)$, medium level $31.4 \%(n=48)$ and poor levels are $4.6 \%$ $(n=7)$. Access to health and social care showed that good levels are $4.6 \%(n=7)$, medium level $29.4 \%$ $(n=45)$ and poor levels are $5.2 \%(n=8)$. On the other hand physical safety and security that good levels are $2 \%(\mathrm{n}=3)$, medium level $46.4 \%(\mathrm{n}=41)$ and poor levels are $2 \%(n=3)$. For the physical environment showed that good levels are $2.6 \%(n=4)$, medium level $42.5 \%$ $(n=65)$ and poor levels are $4.6 \% \quad(n=7)$. Otherwise transport showed that good levels are $1.3 \%(\mathrm{n}=2)$, medium level $27.5 \%(n=42)$ and poor levels are $9.8 \%$ $(n=15)$. 
Table-6: Association between Children with ASD's Social Behaviors with Respondent Physical Health

\begin{tabular}{|l|l|l|l|}
\hline \multicolumn{4}{|l|}{ Physical Health } \\
\hline Social behavior & Chi-square test value & df & P value \\
\hline Complaint/calm & 1.411 & 1 & 0.239 \\
\hline Adaptive social & 1.039 & 1 & 0.038 \\
\hline
\end{tabular}

According to the Table- 6 Association between children with ASD's complaint behavior with respondent physical health the p-value is 0.239 , which is more than 0.05 , and it was not significant. On the other hand association between children with ASD adaptive social with respondent physical health the $\mathrm{p}$ value is 0.038 , which is less than 0.05 , and it was significant. So we can conclude that there was no association ASD children's complaint behavior with parent's physical health.

Table-7: Association between Children with ASD's Problem Behaviors with Respondents Physical Health

\begin{tabular}{|l|l|l|l|}
\hline \multicolumn{5}{|l|}{ Physical Health } & Chi-square test value & df & P value \\
\hline Problem Behavior & 5.381 & 1 & $0.000^{* *}$ \\
\hline Conduct Problem & 4.729 & 1 & $0.000^{* *}$ \\
\hline Insecure /Anxious & 3.760 & 1 & $0.000^{* *}$ \\
\hline Hyperactive & 3.188 & 1 & $0.000^{* *}$ \\
\hline Self-Injury/Stereotypic & 3.182 & 1 & $0.000^{* *}$ \\
\hline Self-Isolated /Ritualistic & 1.934 & 1 & 0.010 \\
\hline Overly Sensitive & \multicolumn{3}{|l}{} \\
\hline
\end{tabular}

In this Table-7 shows that all the characteristics of children with ASD problem behavior like conduct problem, anxious, hyperactive, stereotypic and self isolated are highly significant with respondent physical health (significant \& p value less than 0.05 ). This means children with ASDs problem behavior with parents physical health has higher significant association.

Table-8: Association between Children with ASD's Social Behaviors with Respondents Psychological Health

\begin{tabular}{|l|l|l|l|}
\hline \multicolumn{4}{|l|}{ Psychological Health } \\
\hline Social Behaviors & Chi-square test value & df & P value \\
\hline Complaint/calm & 1.258 & 1 & 0.589 \\
\hline Adaptive social & 1.169 & 1 & 0.005 \\
\hline
\end{tabular}

The Table-8 Shows the association between Children with ASD complaint behaviors with respondent psychological health the $\mathrm{p}$ - value was 0.589 which was more than 0.05 , and it was not significant.
On the other hand association between Children with ASD adaptive social with respondent psychological health the p- value is 0.005 which is less than 0.05 , and it was significant.

Table-9: Association between Children with ASD problem Behaviors with Respondents Psychological Health

\begin{tabular}{|l|l|l|l|}
\hline Psychological Health & Chi-square test value & df & P value \\
\hline Problem behavior & 5.153 & 1 & $0.000^{* *}$ \\
\hline Conduct Problem & 5.243 & 1 & $0.000^{* *}$ \\
\hline Insecure /Anxious & 3.105 & 1 & 0.001 \\
\hline Hyperactive & 2.270 & 1 & 0.092 \\
\hline Self-Injury/Stereotypic & 2.905 & 1 & $0.000^{* *}$ \\
\hline Self-Isolated /Ritualistic & 1.721 & 1 & 0.104 \\
\hline Overly Sensitive & & & \\
\hline
\end{tabular}

The Table-9 shows sub-tasks of problem behavior for children with ASD's are conduct problem, anxious, and self isolated which are highly significant with respondent psychological health because all the $\mathrm{p}$ values are $0.000^{* *}$. But self-injury and overly sensitive $(\mathrm{p}>0.05)$ are not significant with the respondent psychological health.

Table-10: Association between Children with ASD's Social Behaviors with Respondents Social Relationships

\begin{tabular}{|l|l|l|l|}
\hline \multicolumn{4}{|l|}{ Social Relationships } \\
\hline Social behaviors & Chi-square test value & df & p-value \\
\hline Complaint/calm & 1.614 & 1 & 0.139 \\
\hline Adaptive social & 1.363 & 1 & 0.001 \\
\hline
\end{tabular}


The chi-test result showed in Table-10 that adaptive social behaviors is associated significantly $(p<0.05)$ with respondent's social relationships. On the other hand there was no impact on the complaint behavior with the respondent's social relationships.

Table-11: Association between Children with ASD's problem Behaviors with Respondents Social Relationships

\begin{tabular}{|l|l|l|l|}
\hline Social Relationships & Chi-square test value & df & p-value \\
\hline Problem behavior & 5.827 & 1 & $0.000^{* *}$ \\
\hline Conduct Problem & 5.614 & 1 & $0.000^{* *}$ \\
\hline Insecure /Anxious & 3.282 & 1 & 0.004 \\
\hline Hyperactive & 2.690 & 1 & 0.014 \\
\hline Self-Injury/Stereotypic & 2.783 & 1 & 0.002 \\
\hline Self-Isolated /Ritualistic & 2.271 & 1 & 0.001 \\
\hline Overly Sensitive & \multicolumn{3}{|l}{} \\
\hline
\end{tabular}

Table-11 Showed that children with ASD's problem behaviors all sub-tasks were significantly associated with respondent social relationships. All those $\mathrm{p}$ values were less than 0.05 . So we can conclude that children with ASD's problem behavior with parents' social behavior have significant association.

Table-12: Association between Children with ASD's Social Behaviors with Respondents Environment

\begin{tabular}{|l|l|l|l|}
\hline Environment & p-value \\
\hline Social behavior & Chi-square test value & df & pomplaint/calm \\
2.008 & 1 & 0.162 \\
\hline Adaptive social & 1.402 & 1 & 0.037 \\
\hline
\end{tabular}

The Table-12 Showed chi-test result showed that adaptive social behaviors was associated significantly $(\mathrm{p}<0.05)$ with respondent's environment.
On the other hand there were there is no impact on the complaint behavior with the respondents environment.

Table-13: Association between Children with ASD's Problem Behaviors with Respondents Environment

\begin{tabular}{|l|l|l|l|}
\hline Environment & Chi-square test value & df & p-value \\
\hline Problem behavior & 7.040 & 1 & $0.000^{* *}$ \\
\hline Conduct Problem & 6.170 & 1 & $0.000^{* *}$ \\
\hline Insecure /Anxious & 4.481 & 1 & $0.000^{* *}$ \\
\hline Hyperactive & 3.117 & 1 & 0.093 \\
\hline Self-Injury/Stereotypic & 3.749 & 1 & $0.000^{* *}$ \\
\hline Self-Isolated /Ritualistic & 3.165 & 1 & $0.000^{* *}$ \\
\hline Overly Sensitive & 3 & & \\
\hline
\end{tabular}

The Table-13 showed that most of the association between children with ASD problem behaviors with respondent environment was highly significant because the $\mathrm{p}$ value is $0.000 * *$. Only the self-injury $(\mathrm{p}>0.05)$ is not significant. We may conclude that there were no impact associations on the parent's environment domain with children's self-injury behavior.

Table-14: Correlation between Children with ASD's Social Behaviors with Respondents Physical Health

\begin{tabular}{|c|c|c|c|c|}
\hline Age category & Gender & $\begin{array}{l}\text { Spearman Rank } \\
\text { Correlation }\end{array}$ & $\begin{array}{l}\text { Complaint/Physical } \\
\text { Health }\end{array}$ & $\begin{array}{l}\text { Adaptive social/Physical } \\
\text { Health }\end{array}$ \\
\hline \multirow{6}{*}{$\begin{array}{l}22 \text { years to } 36 \\
\text { years }\end{array}$} & \multirow{3}{*}{ Male (Father) } & Correlation Coefficient & -.033 & .037 \\
\hline & & Sig. (2-tailed) & .890 & .876 \\
\hline & & $\mathrm{N}$ & 20 & 20 \\
\hline & \multirow{3}{*}{$\begin{array}{l}\text { Female } \\
\text { (Mother) }\end{array}$} & Correlation Coefficient & .028 & .065 \\
\hline & & Sig. (2-tailed) & .820 & .602 \\
\hline & & $\mathrm{N}$ & 67 & 67 \\
\hline \multirow{6}{*}{$\begin{array}{l}37 \text { years to } 51 \\
\text { years }\end{array}$} & \multirow[t]{3}{*}{ Male (Father) } & Correlation Coefficient & .127 & .352 \\
\hline & & Sig. (2-tailed) & .412 & .019 \\
\hline & & $\mathrm{N}$ & 44 & 44 \\
\hline & \multirow{3}{*}{$\begin{array}{l}\text { Female } \\
\text { (Mother) }\end{array}$} & Correlation Coefficient & -.101 & .057 \\
\hline & & Sig. (2-tailed) & .653 & .803 \\
\hline & & $\mathrm{N}$ & 22 & 22 \\
\hline
\end{tabular}


. Correlation is significant at the 0.05 level (2-tailed).

This Table-14 shows that there is a negative weak correlation between age category from 22 years to 36 years of male (father) respondent and the children with ASD's complaint/physical health $\left(\mathrm{r}_{\mathrm{s}}=-0.033\right)$. Children with ASD's adaptive social/physical health have the positive weak correlation with male respondents age category (22 years to 36 years) as because $\left(r_{s}=0.037\right)$. Besides this there is a positive weak correlation with the age category (22 years to 36 years) of the female (mother) respondents and ASD's both the complaint/physical health $\left(\mathrm{r}_{\mathrm{s}}=0.028\right)$ and adaptive social behavior $\left(r_{s}=0.065\right)$ as because both of these $r_{s}$ value is $<0.25$. In between the age category 37 years to 51 years of male (father) respondent, there is a positive weak correlation with ASD's complaint/physical health $\left(r_{s}<0.25\right)$ also have the positive intermediate correlation with ASD's adaptive social/physical health $\left(r_{s}>0.25\right)$. On the other hand age category from 37 years to 51 years of female (mother) respondents; there is a negative weak correlation with ASD's complaint/physical health $\left(\mathrm{r}_{\mathrm{s}}=-0.101\right)$ and also have the positive weak correlation with the ASD's adaptive social/physical health $\left(r_{\mathrm{s}}=0.057\right)$.

Table-15: Correlation between Children with ASD's Social Behaviors with Respondents Psychological Health

\begin{tabular}{|c|c|c|c|c|}
\hline Age category & Gender & $\begin{array}{l}\text { Spearman Rank } \\
\text { Correlation }\end{array}$ & $\begin{array}{l}\text { Complaint/Psychological } \\
\text { Health }\end{array}$ & $\begin{array}{l}\text { Adaptive } \\
\text { social/Psychological Health }\end{array}$ \\
\hline \multirow{6}{*}{$\begin{array}{l}22 \text { years to } 36 \\
\text { years }\end{array}$} & \multirow[t]{3}{*}{ Male (Father) } & $\begin{array}{l}\text { Correlation } \\
\text { Coefficient }\end{array}$ & .350 & .168 \\
\hline & & Sig. (2-tailed) & .130 & .480 \\
\hline & & $\mathrm{N}$ & 20 & 20 \\
\hline & \multirow[t]{3}{*}{$\begin{array}{l}\text { Female } \\
\text { (Mother) }\end{array}$} & $\begin{array}{l}\text { Correlation } \\
\text { Coefficient }\end{array}$ & $\begin{array}{l}-.011 \\
\end{array}$ & -.038 \\
\hline & & Sig. (2-tailed) & .929 & .760 \\
\hline & & $\mathrm{N}$ & 67 & 67 \\
\hline \multirow{6}{*}{$\begin{array}{l}37 \text { years to } 51 \\
\text { years }\end{array}$} & \multirow[t]{3}{*}{ Male (Father) } & $\begin{array}{l}\text { Correlation } \\
\text { Coefficient }\end{array}$ & .371 & .441 \\
\hline & & Sig. (2-tailed) & .013 & .003 \\
\hline & & $\mathrm{N}$ & 44 & 44 \\
\hline & \multirow[t]{3}{*}{$\begin{array}{l}\text { Female } \\
\text { (Mother) }\end{array}$} & $\begin{array}{l}\text { Correlation } \\
\text { Coefficient }\end{array}$ & -.248 & -.220 \\
\hline & & Sig. (2-tailed) & .265 & .325 \\
\hline & & $\mathrm{N}$ & 22 & 22 \\
\hline
\end{tabular}

In this Table-15, both the age category 22 years to 36 years and 37 years to 51 years of male (father) respondent's psychological health have positive intermediate correlation with ASD children's social behavior except adaptive social/psychological health in between the age limit 22 years to 36 years, here positive weak correlation since $r_{s}=0.168$. All others $r_{s}$ value is greater than 0.25 . Such as complaint/psychological health where $r_{\mathrm{s}}=0.350$ and $\mathrm{r}_{\mathrm{s}}=0.371$ respectively with the age category 22 years to 36 years and 37 years to 51 years.
From 37 years to 51 years of male (father) respondent's psychological health have positive intermediate correlation with adaptive social/psychological health $\left(r_{\mathrm{s}}=0.441\right)$. On the other hand both the age category 22 years to 36 years and 37 years to 51 years of female (mother) respondent's psychological health have negative weak correlation with Children with ASD's both complaint/psychological health and adaptive social/physical health $\left(\mathrm{r}_{\mathrm{s}}<-0.25\right)$.

Table-16: Correlation between Children with ASD's Social Behaviors with Respondents Social Domain

\begin{tabular}{|c|c|c|c|c|}
\hline Age category & Gender & Spearman Rank Correlation & Complaint/Social domain & Adaptive social/ Social domain \\
\hline \multirow{6}{*}{22 years to 36 years } & \multirow[t]{3}{*}{ Male (Father) } & Correlation Coefficient & .380 & .361 \\
\hline & & Sig. (2-tailed) & .099 & .118 \\
\hline & & $\mathrm{N}$ & 20 & 20 \\
\hline & \multirow[t]{3}{*}{ Female (Mother) } & Correlation Coefficient & .044 & -.059 \\
\hline & & Sig. (2-tailed) & .722 & .636 \\
\hline & & $\mathrm{N}$ & 67 & 67 \\
\hline \multirow{6}{*}{37 years to 51 years } & \multirow[t]{3}{*}{ Male (Father) } & Correlation Coefficient & .220 & .235 \\
\hline & & Sig. (2-tailed) & .151 & .125 \\
\hline & & $\mathrm{N}$ & 44 & 44 \\
\hline & \multirow[t]{3}{*}{ Female (Mother) } & Correlation Coefficient & -.213 & -.138 \\
\hline & & Sig. (2-tailed) & .342 & .540 \\
\hline & & $\mathrm{N}$ & 22 & 22 \\
\hline
\end{tabular}


The Table-16 shows that age category 22 years to 36 years of male (father) respondent's social domain has positive intermediate correlation with ASD children's social behavior because both the $r_{s}$ value is greater than 0.25 . Here complaint/social domain's $r_{s}=$ 0.380 and adaptive social/social domain's $r_{s}=0.361$

For mother (female) respondents in between the age category 22 years to 36 years; there is a positive weak correlation and another negative weak correlation with ASD's social behavior respectively with the complaint/social domain $\left(\mathrm{r}_{\mathrm{s}}=0.044\right)$ and adaptive social/social domain $\left(r_{\mathrm{s}}=-0.059\right)$.

In between the age category 37 years to 51 years male (father) respondents have the positive weak correlation with the children with ASD's complaint/social domain $\left(r_{s}=0.220\right)$ and adaptive social/social domain $\left(\mathrm{r}_{\mathrm{s}}=0.235\right)$.

On the other side there is negative weak correlation with the female (mother) respondent as because both of the $r_{s}<-0.235$.

Table-17: Correlation between Children with ASD's Social Behavior with Respondent Environment Domain

\begin{tabular}{|c|c|c|c|c|}
\hline Age category & Gender & $\begin{array}{l}\text { Spearman Rank } \\
\text { Correlation }\end{array}$ & $\begin{array}{l}\text { Complaint/Environment } \\
\text { domain }\end{array}$ & $\begin{array}{l}\text { Adaptive social/ } \\
\text { Environment domain }\end{array}$ \\
\hline \multirow[t]{6}{*}{22 years to 36 years } & \multirow[t]{3}{*}{ Male (Father) } & Correlation Coefficient & -.080 & -.057 \\
\hline & & Sig. (2-tailed) & .736 & .813 \\
\hline & & $\mathrm{N}$ & 20 & 20 \\
\hline & \multirow{3}{*}{$\begin{array}{l}\text { Female } \\
\text { (Mother) }\end{array}$} & Correlation Coefficient & .040 & .025 \\
\hline & & Sig. (2-tailed) & .748 & .839 \\
\hline & & $\mathrm{N}$ & 67 & 67 \\
\hline \multirow{6}{*}{37 years to 51 years } & \multirow[t]{3}{*}{ Male (Father) } & Correlation Coefficient & .194 & .405 \\
\hline & & Sig. (2-tailed) & .207 & .006 \\
\hline & & $\mathrm{N}$ & 44 & 44 \\
\hline & \multirow{3}{*}{$\begin{array}{l}\text { Female } \\
\text { (Mother) }\end{array}$} & Correlation Coefficient & -.444 & -.378 \\
\hline & & Sig. (2-tailed) & .038 & .083 \\
\hline & & $\mathrm{N}$ & 22 & 22 \\
\hline
\end{tabular}

From this Table-17 in between the age category 22 years to 36 years of male (father) respondent's environment domain have the negative weak correlation with the children with ASD's social behavior. Here complaint/environment domain $r_{s}=-$ 0.080 and adaptive social/environment domain $r_{s}=-$ 0.057 . For female in this age category there is positive weak correlation with ASD children's social behavior because both the $r_{s}$ value is less than 0.25. Here complaint/environment domain $r_{s}=0.040$ and adaptive social/environment domain $r_{\mathrm{s}}=0.025$.

For the age category 37 years to 51 years male (father) respondents there is a positive weak correlation and another positive intermediate correlation with ASD's social behavior respectively with the complaint/environment domain $\mathrm{r}_{\mathrm{s}}=0.194$ and adaptive social/environment domain $r_{s}=0.405$. This table for female respondent showed negative intermediate correlation with ASD children's social behavior. Here complaint/environment domain $r_{s}=-0.444$ and adaptive social/environment domain $r_{s}=-0.378$.

We can conclude that age category 22 years to 36 years of male and female respondent's environment domain has been reversed with the 37 years to 51 years of male and female respondent.

Table 18: Correlation between Children with ASD's Problem Behaviors with Respondents Physical Health

\begin{tabular}{|c|c|c|c|c|c|c|c|c|}
\hline $\begin{array}{c}\text { Age } \\
\text { category }\end{array}$ & Gender & $\begin{array}{l}\text { Spearman Rank } \\
\text { Correlation }\end{array}$ & $\begin{array}{l}\text { Conduct } \\
\text { Problem/ } \\
\text { Physical } \\
\text { Health } \\
\end{array}$ & $\begin{array}{l}\text { Insecure } \\
\text { /Physical } \\
\text { Health }\end{array}$ & $\begin{array}{l}\text { Hyperactive/P } \\
\text { hysical Health }\end{array}$ & $\begin{array}{l}\text { Self-Injury/ } \\
\text { Physical } \\
\text { Health }\end{array}$ & $\begin{array}{l}\text { Self- } \\
\text { Isolated } \\
\text { /Physical } \\
\text { Health } \\
\end{array}$ & $\begin{array}{l}\text { Overly } \\
\text { Sensitive/ } \\
\text { Physical Health }\end{array}$ \\
\hline \multirow{6}{*}{$\begin{array}{c}22 \text { years to } \\
36 \text { years }\end{array}$} & \multirow[t]{3}{*}{$\begin{array}{l}\text { Male } \\
\text { (Father) }\end{array}$} & $\begin{array}{l}\text { Correlation } \\
\text { Coefficient }\end{array}$ & .546 & .614 & .233 & .062 & .173 & .142 \\
\hline & & Sig. (2-tailed) & .013 & .004 & .323 & .797 & .466 & .550 \\
\hline & & $\mathrm{N}$ & 20 & 20 & 20 & 20 & 20 & 20 \\
\hline & \multirow[t]{3}{*}{$\begin{array}{l}\text { Female } \\
\text { (Mother) }\end{array}$} & $\begin{array}{l}\text { Correlation } \\
\text { Coefficient } \\
\end{array}$ & .172 & .212 & .044 & -.060 & -.052 & .150 \\
\hline & & Sig. (2-tailed) & .164 & .085 & .724 & .628 & .674 & .227 \\
\hline & & $\mathrm{N}$ & 67 & 67 & 67 & 67 & 67 & 67 \\
\hline \multirow{6}{*}{$\begin{array}{l}37 \text { years to } \\
51 \text { years }\end{array}$} & \multirow[t]{3}{*}{$\begin{array}{l}\text { Male } \\
\text { (Father) }\end{array}$} & $\begin{array}{l}\text { Correlation } \\
\text { Coefficient } \\
\end{array}$ & .084 & .126 & .084 & .031 & -.058 & -.037 \\
\hline & & Sig. (2-tailed) & .586 & .415 & .588 & .843 & .709 & .812 \\
\hline & & $\mathrm{N}$ & 44 & 44 & 44 & 44 & 44 & 44 \\
\hline & \multirow[t]{3}{*}{$\begin{array}{l}\text { Female } \\
\text { (Mother) }\end{array}$} & $\begin{array}{l}\text { Correlation } \\
\text { Coefficient }\end{array}$ & .051 & .198 & .027 & .280 & -.004 & -.121 \\
\hline & & Sig. (2-tailed) & .821 & .378 & .906 & .207 & .986 & .593 \\
\hline & & $\mathrm{N}$ & 22 & 22 & 22 & 22 & 22 & 22 \\
\hline
\end{tabular}


**. Correlation is significant at the 0.01 level (2-tailed).

*. Correlation is significant at the 0.05 level (2-tailed).

The Table-18 shows Spearman's rank correlation is used to examine the correlation among the children with ASD's problem behavior and respondent physical health with age categories and gender. In this table the age category of male (father) from 22 years to 36 years; there are positive intermediate correlation with conduct problem/physical health $\left(r_{s}=0.546\right)$ and insecure /physical health $\left(r_{s}=0.614\right)$. Others problem behaviors are positive weak correlation with male respondent's physical health like hyperactive/physical health $r_{s}=0.233$, self-injury/physical health $r_{s}=0.062$, selfisolated/physical health $r_{s}=0.173$ and overly sensitive/physical health $r_{s}=0.142$.

For female 22-36 years age category, there are weak correlation with conduct problem/physical health $\left(r_{s}=0.172\right)$, insecure /physical health $\left(r_{s}=0.212\right)$, hyperactive/physical health $\left(r_{s}=0.044\right)$ and overly sensitive/physical health $\left(\mathrm{r}_{\mathrm{s}}=0.150\right)$. There are negative weak correlation with the self-injury/physical health $\left(\mathrm{r}_{\mathrm{s}}=-0.060\right)$ and selfisolated/physical health $\left(\mathrm{r}_{\mathrm{s}}=-0.052\right)$.

In between the age category 37 years to 51 years male (father) respondent have positive weak correlation with the conduct problem/physical health $\left(r_{s}=0.084\right)$, insecure/physical health $\left(r_{s}=0.126\right)$, hyperactive/physical health $\left(r_{s}=0.084\right)$ and self-injury/physical health $\left(r_{s}=0.031\right)$. Self-isolated/physical health $\left(r_{s}=-0.058\right)$ and overly sensitive/physical health $\left(r_{s}=-0.037\right)$; those two component are negative weak correlation with ASD children's problem behavior.

For female 37-51 years age category there are positive weak correlation with conduct problem/physical health $\left(r_{s}=0.051\right)$, insecure/physical health $\left(r_{s}=0.198\right)$, hyperactive/physical health $\left(r_{s}=0.027\right)$ and positive intermediate correlation with self-injury/physical health $\left(\mathrm{r}_{\mathrm{s}}=0.280\right)$. Both self-isolated/physical health $\left(\mathrm{r}_{\mathrm{s}}=-0.004\right)$ and overly sensitive/physical health $\left(\mathrm{r}_{\mathrm{s}}=-0.121\right)$; those two component are negative weak correlation with ASD children's problem behavior.

Table-19: Correlation between Children with ASD's Problem Behaviors with Respondents Psychological Health

\begin{tabular}{|c|c|c|c|c|c|c|c|c|}
\hline $\begin{array}{l}\text { Age } \\
\text { category }\end{array}$ & Gender & $\begin{array}{l}\text { Spearman } \\
\text { Rank } \\
\text { Correlation }\end{array}$ & $\begin{array}{l}\text { Conduct } \\
\text { Problem/Psy } \\
\text { chological } \\
\text { Health }\end{array}$ & $\begin{array}{l}\text { Insecure / } \\
\text { Psychologi } \\
\text { cal Health }\end{array}$ & $\begin{array}{l}\text { Hyperactive/ } \\
\text { Psychologica } \\
\text { I Health }\end{array}$ & $\begin{array}{l}\text { Self-Injury/ } \\
\text { Psychologica } \\
\text { l Health }\end{array}$ & $\begin{array}{l}\text { Self-Isolated/ } \\
\text { Psychologica } \\
\text { I Health }\end{array}$ & $\begin{array}{l}\text { Overly } \\
\text { Sensitive/ } \\
\text { Psychologica } \\
\text { l Health }\end{array}$ \\
\hline \multirow{6}{*}{$\begin{array}{l}22 \text { years } \\
\text { to } 36 \\
\text { years }\end{array}$} & \multirow[t]{3}{*}{$\begin{array}{l}\text { Male } \\
\text { (Father) }\end{array}$} & $\begin{array}{l}\text { Correlation } \\
\text { Coefficient }\end{array}$ & .336 & .534 & -.203 & -.215 & -.122 & -.114 \\
\hline & & Sig. (2-tailed) & .147 & .015 & .391 & .362 & .610 & .634 \\
\hline & & $\mathrm{N}$ & 20 & 20 & 20 & 20 & 20 & 20 \\
\hline & \multirow[t]{3}{*}{$\begin{array}{l}\text { Female } \\
\text { (Mother) }\end{array}$} & $\begin{array}{l}\text { Correlation } \\
\text { Coefficient }\end{array}$ & .185 & .261 & .037 & .000 & -.011 & .151 \\
\hline & & Sig. (2-tailed) & .133 & .033 & .766 & .994 & .928 & .223 \\
\hline & & $\mathrm{N}$ & 67 & 67 & 67 & 67 & 67 & 67 \\
\hline \multirow{6}{*}{$\begin{array}{l}37 \text { years } \\
\text { to } 51 \\
\text { years }\end{array}$} & \multirow[t]{3}{*}{$\begin{array}{l}\text { Male } \\
\text { (Father) }\end{array}$} & $\begin{array}{l}\text { Correlation } \\
\text { Coefficient }\end{array}$ & .262 & .358 & .028 & .028 & .026 & .023 \\
\hline & & Sig. (2-tailed) & .086 & .017 & .855 & .855 & .869 & .885 \\
\hline & & $\mathrm{N}$ & 44 & 44 & 44 & 44 & 44 & 44 \\
\hline & \multirow[t]{3}{*}{$\begin{array}{l}\text { Female } \\
\text { (Mother) }\end{array}$} & $\begin{array}{l}\text { Correlation } \\
\text { Coefficient }\end{array}$ & -.295 & -.271 & $-.479^{*}$ & -.319 & -.424 & -.414 \\
\hline & & Sig. (2-tailed) & .183 & .222 & .024 & .148 & .049 & .055 \\
\hline & & $\mathrm{N}$ & 22 & 22 & 22 & 22 & 22 & 22 \\
\hline
\end{tabular}

Table 19. shows Spearman's rank correlation is used to examine the correlation among the children with ASD's problem behavior and respondent psychological health with age categories and gender. In this table the age category of male (father) from 22-36 years; there are positive intermediate correlation with conduct problem/psychological health $\left(r_{s}=0.336\right)$ and insecure/psychological health $\left(r_{\mathrm{s}}=0.534\right)$.

Others problem behaviors are negative weak correlation with male respondent's psychological health like hyperactive/psychological health $\left(r_{s}=-0.203\right)$, selfinjury/psychological health $\left(\mathrm{r}_{\mathrm{s}}=-0.215\right)$, self- isolated/psychological health $\left(r_{s}=-0.122\right)$ and overly sensitive/psychological health $\left(r_{s}=-0.114\right)$.

For female 22-36 years age category, there are positive weak correlation with conduct problem/psychological health $\quad\left(r_{s}=0.185\right)$, hyperactive/psychological health $\left(r_{s}=0.037\right)$, selfinjury/psychological health $\left(r_{s}=0.000\right)$ and overly sensitive/psychological health $\left(r_{\mathrm{s}}=0.151\right)$. There are negative weak correlation with self-isolated/ psychological health $\left(r_{\mathrm{s}}=-0.011\right)$. Also have the positive intermediate correlation with insecure/psychological health $\left(r_{\mathrm{s}}=0.261\right)$. 
In between the age category 37 years to 51 years male (father) respondent have positive intermediate correlation with ASD children's problem behavior like the conduct problem/psychological health $\left(r_{\mathrm{s}}=0.262\right)$, insecure/psychological health $\left(r_{\mathrm{s}}=0.358\right)$.

There are positive weak correlation with hyperactive/psychological health $\left(\mathrm{r}_{\mathrm{s}}=0.028\right)$, selfinjury/psychological health $\left(\mathrm{r}_{\mathrm{s}}=0.028\right)$, self-isolated/ psychological health $\left(\mathrm{r}_{\mathrm{s}}=0.026\right)$ and overly sensitive/psychological health $\left(\mathrm{r}_{\mathrm{s}}=0.023\right)$.

From 37-51 years of age category female psychological health; all those component's values are less than 0.25 and all are negative. So there are negative intermediate correlations with ASD children's problem behavior.

Table-20: Correlation between Children with ASD's Problem Behaviors with Respondents Social Domain

\begin{tabular}{|c|c|c|c|c|c|c|c|c|}
\hline $\begin{array}{l}\text { Age } \\
\text { category }\end{array}$ & Gender & $\begin{array}{l}\text { Spearman } \\
\text { Rank } \\
\text { Correlation }\end{array}$ & $\begin{array}{l}\text { Conduct } \\
\text { Problem/Social } \\
\text { Domain }\end{array}$ & $\begin{array}{l}\text { Insecure / } \\
\text { Social } \\
\text { Domain }\end{array}$ & $\begin{array}{l}\text { Hyperactive/ } \\
\text { Social } \\
\text { Domain }\end{array}$ & $\begin{array}{l}\text { Self- } \\
\text { Injury/ } \\
\text { Social } \\
\text { Domain }\end{array}$ & $\begin{array}{l}\text { Self- } \\
\text { Isolated/ } \\
\text { Social } \\
\text { Domain }\end{array}$ & $\begin{array}{l}\text { Overly } \\
\text { Sensitive/ } \\
\text { Social } \\
\text { Domain }\end{array}$ \\
\hline \multirow{6}{*}{$\begin{array}{lr}22 & \text { years } \\
\text { to } & 36 \\
\text { years }\end{array}$} & \multirow[t]{3}{*}{$\begin{array}{l}\text { Male } \\
\text { (Father) }\end{array}$} & $\begin{array}{l}\text { Correlation } \\
\text { Coefficient }\end{array}$ & .591 & .712 & .293 & -.002 & .053 & .154 \\
\hline & & Sig. (2-tailed) & .006 & .000 & .209 & .995 & .825 & .516 \\
\hline & & $\mathrm{N}$ & 20 & 20 & 20 & 20 & 20 & 20 \\
\hline & \multirow[t]{3}{*}{$\begin{array}{l}\text { Female } \\
\text { (Mother) }\end{array}$} & $\begin{array}{l}\text { Correlation } \\
\text { Coefficient }\end{array}$ & .311 & .330 & .168 & .169 & .100 & .243 \\
\hline & & Sig. (2-tailed) & .011 & .006 & .175 & .173 & .419 & .047 \\
\hline & & $\mathrm{N}$ & 67 & 67 & 67 & 67 & 67 & 67 \\
\hline \multirow{6}{*}{$\begin{array}{lr}37 & \text { years } \\
\text { to } & 51 \\
\text { years }\end{array}$} & \multirow[t]{3}{*}{$\begin{array}{l}\text { Male } \\
\text { (Father) }\end{array}$} & $\begin{array}{l}\text { Correlation } \\
\text { Coefficient }\end{array}$ & .050 & .158 & .006 & .065 & .015 & .020 \\
\hline & & Sig. (2-tailed) & .746 & .305 & .968 & .676 & .922 & .900 \\
\hline & & $\mathrm{N}$ & 44 & 44 & 44 & 44 & 44 & 44 \\
\hline & \multirow[t]{3}{*}{$\begin{array}{l}\text { Female } \\
\text { (Mother) }\end{array}$} & $\begin{array}{l}\text { Correlation } \\
\text { Coefficient } \\
\end{array}$ & .206 & .286 & .062 & .352 & -.018 & .049 \\
\hline & & Sig. (2-tailed) & .357 & .198 & .785 & .108 & .937 & .828 \\
\hline & & $\mathrm{N}$ & 22 & 22 & 22 & 22 & 22 & 22 \\
\hline
\end{tabular}

Table 20. shows Spearman's rank correlation is used to examine the correlation among the children with ASD's problem behavior and respondent social domain with age categories and gender. In this table the age category of male (father) from 22-36 years; there are positive intermediate correlation with conduct problem/ social domain $\left(\mathrm{r}_{\mathrm{s}}=0.591\right)$, insecure/ social domain $\left(r_{\mathrm{s}}=0.712\right)$ and hyperactive/social domain $\left(r_{s}=0.293\right)$. Negative weak correlation with male respondent's self-injury/social domain $\left(r_{s}=-0.002\right)$. Positive weak correlation with self-isolated/social domain $\left(r_{s}=0.053\right)$ and overly sensitive/social domain $\left(r_{s}=0.151\right)$.

For female in this age category; there are positive intermediate correlation with conduct problem/ social domain $\left(r_{s}=0.311\right)$ and insecure/ social domain $\left(r_{s}=0.330\right)$. Without those two domains all others have the positive weak correlation with ASD children's problem behavior. Such as hyperactive/social domain $\left(r_{s}=0.168\right)$, self-injury/social domain $\left(r_{s}=0.169\right)$, selfisolated/social domain $\left(r_{s}=0.100\right)$ and overly sensitive/social domain $\left(r_{s}=0.243\right)$.

From the age category 22-36 years for male respondent social domain have the positive weak correlation with ASD children's problem behavior, as because all these domain's $r_{\mathrm{s}}$ values are less than 0.25. On other hand in this age category for female respondent; positive weak correlation with ASD children's problem behavior. Such as conduct problem/ social domain $\left(r_{s}=0.206\right)$, hyperactive/social domain $\left(r_{s}=0.062\right)$ and overly sensitive/social domain $\left(\mathrm{r}_{\mathrm{s}}=0.049\right)$.

Positive intermediate correlation with insecure/ social domain $\left(r_{s}=0.286\right)$ and self-injury/social domain $\left(r_{s}=0.352\right)$. There also have a negative weak correlation with self-isolated/social domain $\left(r_{s}=-0.018\right)$. 
Table-21: Correlation between Children with ASD's Problem Behaviors with Respondents Environment Domain

\begin{tabular}{|c|c|c|c|c|c|c|c|c|}
\hline $\begin{array}{l}\text { Age } \\
\text { category }\end{array}$ & Gender & $\begin{array}{l}\text { Spearman } \\
\text { Rank } \\
\text { Correlation }\end{array}$ & $\begin{array}{l}\text { Conduct } \\
\text { Problem/ } \\
\text { Environmen } \\
\text { t Domain } \\
\end{array}$ & $\begin{array}{l}\text { Insecure/ } \\
\text { Environmen } \\
\text { t Domain }\end{array}$ & $\begin{array}{l}\text { Hyperactive/ } \\
\text { Environment } \\
\text { Domain }\end{array}$ & $\begin{array}{l}\text { Self-Injury/ } \\
\text { Environment } \\
\text { Domain }\end{array}$ & $\begin{array}{l}\text { Self-Isolated// } \\
\text { Environment } \\
\text { Domain }\end{array}$ & $\begin{array}{l}\text { Overly } \\
\text { Sensitive/ } \\
\text { Environment } \\
\text { Domain } \\
\end{array}$ \\
\hline \multirow{6}{*}{$\begin{array}{l}22 \text { years } \\
\text { to } 36 \\
\text { years }\end{array}$} & \multirow[t]{3}{*}{$\begin{array}{l}\text { Male } \\
\text { (Father) }\end{array}$} & $\begin{array}{l}\text { Correlation } \\
\text { Coefficient }\end{array}$ & .349 & .435 & -.031 & -.310 & -.159 & -.095 \\
\hline & & $\begin{array}{l}\text { Sig. } \\
\text { tailed) }\end{array}$ & .131 & .055 & .896 & .184 & .504 & .690 \\
\hline & & $\mathrm{N}$ & 20 & 20 & 20 & 20 & 20 & 20 \\
\hline & \multirow[t]{3}{*}{$\begin{array}{l}\text { Female } \\
\text { (Mother) }\end{array}$} & $\begin{array}{l}\text { Correlation } \\
\text { Coefficient }\end{array}$ & .184 & .189 & .045 & -.044 & -.041 & .121 \\
\hline & & $\begin{array}{l}\text { Sig. } \\
\text { tailed) }\end{array}$ & .136 & .126 & .718 & .722 & .743 & .328 \\
\hline & & $\mathrm{N}$ & 67 & 67 & 67 & 67 & 67 & 67 \\
\hline \multirow{6}{*}{$\begin{array}{l}37 \text { years } \\
\text { to } 51 \\
\text { years }\end{array}$} & \multirow[t]{3}{*}{$\begin{array}{l}\text { Male } \\
\text { (Father) }\end{array}$} & $\begin{array}{l}\text { Correlation } \\
\text { Coefficient }\end{array}$ & $.374^{*}$ & $.436^{* * *}$ & .240 & $.320^{*}$ & .124 & .297 \\
\hline & & $\begin{array}{l}\text { Sig. } \\
\text { tailed) }\end{array}$ & .012 & .003 & .117 & .034 & .424 & .050 \\
\hline & & $\mathrm{N}$ & 44 & 44 & 44 & 44 & 44 & 44 \\
\hline & \multirow[t]{3}{*}{$\begin{array}{l}\text { Female } \\
\text { (Mother) }\end{array}$} & $\begin{array}{l}\text { Correlation } \\
\text { Coefficient }\end{array}$ & .037 & -.077 & $-.438^{*}$ & -.253 & -.267 & -.255 \\
\hline & & $\begin{array}{l}\text { Sig. } \\
\text { tailed) }\end{array}$ & .871 & .734 & .041 & .256 & .230 & .252 \\
\hline & & $\mathrm{N}$ & 22 & 22 & 22 & 22 & 22 & 22 \\
\hline
\end{tabular}

Table-21 shows Spearman's rank correlation is used to examine the correlation among the children with ASD's problem behavior and respondent environment domain with age categories and gender. In this table the age category of male (father) from 22-36 years; there are positive intermediate correlation with conduct problem/environment domain $\left(\mathrm{r}_{\mathrm{s}}=0.349\right)$, insecure/environment domain $\left(r_{s}=0.435\right)$. All other component is negative correlation with ASD's problem behavior because $r_{\mathrm{s}}$ are negative value.

In this age limit (22-36) for female there are positive weak correlation between the conduct problem/environment domain $\quad\left(r_{\mathrm{s}}=0.184\right)$, insecure/environment domain $\quad\left(r_{s}=0.189\right)$, hyperactive/environment domain $\left(r_{s}=0.045\right)$ and overly sensitive/environment domain $\left(\mathrm{r}_{\mathrm{s}}=0.121\right)$. Selfinjury/environment domain $\left(\mathrm{r}_{\mathrm{s}}=-0.044\right)$ and selfisolated/environment domain $\left(r_{s}=-0.041\right)$ have the negative correlation.

In between the age category 37-51 years male respondents all domains are positively correlated with the ASD children's problem behavior.

On other hand for female age category 37-51 years; all the domain value is negative except conduct problem/environment domain $\left(\mathrm{r}_{\mathrm{s}}=0.037\right)$. So there is negative correlation with ASD children's problem behavior (as $r_{s}$ negative value) except conduct problem/environment domain.

\section{DISCUSSION}

This study shows that total 153 parents of children with autism spectrum disorders respondents participated in this study in which $56.9 \%$ parents of 22 36 years age, $43.1 \%$ of $37-51$ years age and also mean \pm SD $(35.37 \pm 6.828)$. From the patents $41.8 \%$ are father and $58.2 \%$ are mother. Here $41.8 \%$ parents are illiterate, $11.8 \%$ completed primary education, $17.0 \%$ S.S.C, $25.3 \%$ H.S.C and graduate, and post graduate completed $9.8 \%$. Most of the parents $(44.4 \%)$ are housewife and $30.1 \%$ service holder, $12.4 \%$ business man, $11.8 \%$ day labor/worker and $1.3 \%$ others. Most of the parents are middle income group (47.7\%), 37.3\% bottom income group and $15.0 \%$ top income group. The average age and standard deviation of children with ASD is $(6.44 \pm 2.042)$ and from these age male child are $56.9 \%$ and 43.1 are female. The age category of the children with ASD 3 years to 6 years is $51.0 \%$ and 7 years to 10 years is $49.0 \%$.

Parents of autism spectrum disorder had shown significant impairment $(\mathrm{p}<0.001)$ than the other two groups [6]. Children with autism spectrum disorder have problem in social interaction including expressing affection towards parents and often these parents are denied of the fundamental rewards of parenthood. Many parents of children with autism spectrum disorder tried to avoid social situations like meeting friends and relatives to avoid embarrassments, and some felt stigmatized in public situations due to the challenging behavior shown by their children, in addition to this 
some parents also found lack of or absence of spouse support. Parent of children with autism spectrum disorder showed significant impairment in this domain $(\mathrm{p}<0.001)$ compared to control group and physically disabled group.

The NCBRF [12] are changes on the Conduct Problem subscale were highly significant at end point and there was a significant effect from the first week onward $(p<.001)$. The decline in symptom ratings from baseline for the placebo group was 6.8 (20.9\%), whereas the reduction for the risperidone group was 15.8 (47.3\%). In addition, the Adaptive Social subscale from the Social Competence section showed significant improvement, and all except the Self-Injury and Overly Sensitive subscales showed a statistically significant advantage for the risperidone-treated group.

In this study found that parents of children with autism are present in significant association between all the four domains of quality of life- physical domain, psychological domain, social domain and environment domain with all the characteristics of children with ASDs problem behavior as conduct problem, anxious, hyperactive, stereotypic, self-isolated and overly sensitive $(\mathrm{p}<0.05)$. There is no association between the children with ASDs social competence with four domain of quality of life. According to the [12] investigated that a study which results suggests of highly significant impairment $(\mathrm{p}<0.001)$ in the quality of life of parent $\mathrm{s}$ of children with autism spectrum disorder than of physical disability or of normal healthy children. The quality of life impairment could be because parents of autism spectrum disorder children experience greater anxiety and tension than parents of non-disabled children. In the present study, it has been found that parents of children with autism showed a significant impairment of QoL. Forty three percent of the total sample met screening cut-off criteria for at least one anxiety disorder. Higher levels of anxiety on the 20-item CASI scale were associated with higher IQ, the presence of functional language use, and with higher levels of stereotyped behaviors. In children with higher IQ, anxiety was also associated with greater impairment in social reciprocity [13].

In the other hand another study of Australia, there were showed that the parents/caregivers of a child with an autism spectrum disorder (ASD) was conducted to examine the relationship between ASD characteristics, family functioning and coping strategies, including a child with ASD places considerable stress on the family. In this study also found that these caregivers had healthy self-esteem, although they reported somewhat lower marital happiness, family cohesion and family adaptability than did norm groups. Coping strategies were not significant predictors of these outcome variables which highlight the need for support programes to target family and relationship variables as well as ASD children and their behaviors', in order to sustain the family unit and improve quality of life for parents and caregivers as well as those children [14]. In contrast with these literatures, along with the current study findings about the relationship among parents of children with autism and behavior disorders experienced statistically and clinically higher levels of parenting stress than parents in the other two groups (Down syndrome and behavior disorder). In this study also found that parents of children with behavior disorders reported that their children presented behavioral difficulties that were statistically and clinically more passionate and numerous than those of all other children. Mothers of children with autism and behavior disorders experienced statistically and clinically higher levels of dysphoria than mothers in the other two groups, which appeared to be specifically related to the stresses of parenting exceptional children rather than to personal dysfunction.

Spearman's rank correlation is used to examine the correlation among the respondent quality of life with age categories and gender. The age category of male (father) from 22 years to 36 years; there were positive intermediate correlation with physical/social $\left(\mathrm{r}_{\mathrm{s}=}=0.469\right), \quad$ physical/environment $\quad\left(\mathrm{r}_{\mathrm{s}=} 0.749\right)$, psychological/social $\quad\left(\mathrm{r}_{\mathrm{s}=0.592), \quad \text { psychological/ }}\right.$ environment $\left(r_{\mathrm{s}=}=0.413\right)$, social/environment $\left(r_{\mathrm{s}=} 0.503\right)$ and also have the positive weak correlation with physical/psychological hence $r_{s=0} 0.211$ which $r_{s}$ value is lower than 0.25 . On the other hand age category of female (mother) from age 22 years to 36 years; there be a positive strong correlation with the entire component of mother's quality of life. In between the age category 37 years to 51 years male (father) respondents have the positive weak correlation with physical /psychological $\left(r_{\mathrm{s}=} 0.216\right)$ and physical /environment $\left(\mathrm{r}_{\mathrm{s}=} 0.233\right)$. Except these two components all others have the positive intermediate correlation in between male (father) respondent's age category with respondent's quality of life. Besides age category 37 years to 51 years female (mother) respondents have the positive intermediate correlation with the entire component of mother's quality of life. For the female (mother) respondents of physical health showed positive intermediate correlation with social behavior of children with ASD and otherwise male (father) respondents showed that inverse weak correlation.

Both mother and father were showed that the positive correlation between physical health with children's problem behaviors (conduct problem, insecure, hyperactive) on the other hand inverse weak correlation has been showed with self-injury, selfisolated and overly sensitive. Parenting context for parents of children with Autism Spectrum Disorders is extremely stressful and is one that creates unique parenting challenges and also indicates that there is a strong correlation between the quality of parenting and children's distress and behavior problems [15]. 
22 years to 36 years of ages male respondents showed that the inverse weak correlation between ASDs problem behavior (hyperactive, self-injury, selfisolated and overly sensitive) with psychological health another things that positive intermediate correlation has been showed with problem behavior (conduct problem and insecure). For female in this age category showed that positive weak correlation with problem behavior except self-isolated. The age category of 37 years to 51years of the female respondent showed that the inverse intermediate correlation between ASD children's problem behavior with psychological health, whereas male respondents were showed that the positive weak correlation. For the social relationship of both parent showed the positive correlation with problem behavior (conduct problem, insecure, hyperactive and overly sensitive) except self-injury and self -isolated.

About the female respondent of environment domain showed that the inverse correlation among the problem behaviour (hyperactive, insecure, self-injury, self-isolated and overly sensitive) except conduct problem. For the male respondent showed the positive weak correlation with the ASD's problem behavior. One of the study in Riyadh, showed statistically significant differences in the level of quality of life and its domains among the participants due to the impact of severity of disability, where differences were in favor of the mild group. This study also justified in light of the presence of a disabled child in the family of severe and moderate disability is a source of pressure for the family and preventing them from practicing their activities of daily life, where their care and requirements are different compared to those of mild disability. As well as the needs of the various requirements of the different devices representing a source of psychological pressures, which are reflected at the level of psychological and physical health of the parents, in addition to the extra-financial [16]. In the other hand another study of Australia, used the Spearman correlations between the four WHOQOLBref domains were Physical/Psychological rs $=0.64$, physical/social rs $=0.37$, physical/environment $\mathrm{rs}=0.50$; psychological/social rs $=0.53$, psychological/ environment $\mathrm{rs}=0.59$; and social/environment $\mathrm{rs}=0.45$ by examination of the impacts of health conditions or health interventions in different societies and cultures [17].

Lecavalier et al., have done a study about the relationship among behavior of ASD and other group and in this study showed that the ASD children had less positive and more problematic behaviors on all subscales. Also showed that only subscale for which there was no significant difference for both parent and teacher ratings were self-injury/stereotypic. Parents of children with ASD are at greater risk for a variety mental health and social problems, including: low levels of psychosocial wellbeing, depression, social isolation, vocational problems, and difficulties with one's family life [18]. In addition, problem behaviors of the child with ASD and a strained parent-child relationship may have an impact on the entire family system. Through this study, it was concluded that if ASD's problems behavior is increased then respondent quality of life will be decreased.

\section{CONCLUSION}

This study was conducted with the purpose of finding the quality of life of parents of children with autism spectrum disorder and behavioural aspects of children with autism spectrum disorders. The results showed that the level of quality of life among the participants was medium, and the results showed statistically significant of quality of life domain among the participants due to the problem behavior of children with autism spectrum disorder. So in this study has concluded that the children with ASD's behavioral aspects were correlated to the parent's physical health, psychological, social relationships and environmental domain. The quality of life impairment parents of autism spectrum disorder children experience greater anxiety and hyperactivity, insecure and self-injury behavior.

Acknowledgments: The researchers are highly appreciative to the Centre for the Rehabilitation of the Paralysed (CRP) authority to give opportunity to accomplish the study and we wish to thank all of the participants who participated in the study for sharing their time and experiences.

Conflict of Interest: No conflict of interest.

Funding: This was a self-funded research project.

\section{REFERENCES}

1. Stefanatos, G. A. (2008). Regression in autistic spectrum disorders. Neuropsychology review, 18(4), 305-319.

2. Masi, A., DeMayo, M. M., Glozier, N., \& Guastella, A. J. (2017). An overview of autism spectrum disorder, heterogeneity and treatment options. Neuroscience bulletin, 33(2), 183-193.

3. Chan, K. K. S., \& Lam, C. B. (2016). Parental maltreatment of children with autism spectrum disorder: A developmental-ecological analysis. Research in Autism Spectrum Disorders, 32, 106-114.

4. Sterling, L., Dawson, G., Estes, A., \& Greenson, J. (2008). Characteristics associated with presence of depressive symptoms in adults with autism spectrum disorder. Journal of autism and developmental disorders, 38(6), 1011-1018.

5. Moyson, T., \& Roeyers, H. (2011). The quality of life of siblings of children with autism spectrum disorder. Exceptional Children, 78(1), 41-55. 
6. Vasilopoulou, E., \& Nisbet, J. (2016). The quality of life of parents of children with autism spectrum disorder: A systematic review. Research in Autism Spectrum Disorders, 23, 36-49.

7. Dickinson, K., \& Place, M. (2016). Living with children with autistic spectrum condition: parental stress and the impact upon family functioning. Advances in Social Sciences Research Journal, 3(3), 110-122.

8. Disability [Internet]. Who.int. 2020 [cited 1 October 2020]. Available from: https://www.who.int/healthtopics/disability\#tab=tab_1

9. Dardas, L. A. (2014). Stress, coping strategies, and quality of life among Jordanian parents of children with Autistic Disorder. Autism, 4(127), 2.

10. Horowitz, F. D. Review of Behavioral Teratogenesis and Behavioral Mutagenesis: A Primer in Abnormal Development. PsycCRITIQUES, 35(4):401-402.

11. Fader, A. N., Frasure, H. E., Gil, K. M., Berger, N. A., \& von Gruenigen, V. E. (2011). Quality of life in endometrial cancer survivors: what does obesity have to do with it?. Obstetrics and gynecology international, 2011.1-6.

12. Bell, C. (1994). DSM-IV: Diagnostic and Statistical Manual of Mental Disorders. JAMA: The Journal of the American Medical Association. 272(10):828.

13. Sukhodolsky, D. G., Scahill, L., Gadow, K. D., Arnold, L. E., Aman, M. G., McDougle, C. J., ... \& Vitiello, B. (2008). Parent-rated anxiety symptoms in children with pervasive developmental disorders: Frequency and association with core autism symptoms and cognitive functioning. Journal of abnormal child psychology, 36(1), 117-128.

14. Tsutsumi, A., Izutsu, T., Kato, S., Islam, M. A., Yamada, H. S., Kato, H., \& Wakai, S. (2006). Reliability and validity of the Bangla version of WHOQOL BREF in an adult population in Dhaka, Bangladesh. Psychiatry and Clinical Neurosciences, 60(4), 493-498.

15. Rezendes, D. L., \& Scarpa, A. (2011). Associations between parental anxiety/depression and child behavior problems related to autism spectrum disorders: The roles of parenting stress and parenting self-efficacy. Autism Research and Treatment, 2011:1-10.

16. Willis, K., Timmons, L., Pruitt, M., Schneider, H. L., Alessandri, M., \& Ekas, N. V. (2016). The relationship between optimism, coping, and depressive symptoms in Hispanic mothers and fathers of children with autism spectrum disorder. Journal of autism and developmental disorders, 46(7), 2427-2440.

17. Lupón, M., Armayones, M., \& Cardona, G. (2018). Quality of life among parents of children with visual impairment: A literature review. Research in developmental disabilities, 83 , 120-131.

18. Higgins, D. J., Bailey, S. R., \& Pearce, J. C. (2005). Factors associated with functioning style and coping strategies of families with a child with an autism spectrum disorder. Autism, 9(2), 125137. 